\title{
Economic Growth: Measuring the Essential Elements
}

\section{Srihari T*, Vinay CV}

${ }^{1}$ Center for Biotechnology, Institute of Science and Technology, Jawaharlal Nehru Technological University, Hyderabad, India

${ }^{2}$ Department of Human Resource development, Andhra Pradesh productivity council, Hyderabad, India

\section{Introduction}

Economy defines that people show much interest and passion of using resources which are available by talent and time like techniques, buildings, lands, equipment's. The stature of economy reflects the growth of a society or country. Maintaining proper economy depends on the appropriate use of human resources as well as natural or other resources available along with timely decision and forecasting [1].

It shows the activities involved in country development from the child to an adult based upon their usage in their requirements. Numerous innovative strategy and skilled manpower made $21^{\text {st }}$ century as a phase of growth in economics for developing countries like India. The political system plays a major role in by contributing towards the country's economics for overall growth and development. Even though India has a huge population, yet there is an increase in growth in all the sectors like agriculture, information technology, automotive sector, pharmaceuticals, research labs, entertainment zones, tourism industry etc. It is a vision that by 2020 India will be the front runner in economics by increasing its fiscal and deficits rates due to rapid increase in the usage of available resources and by promoting the industrial sectors.

Stable improvement is being observed in uplifting the people under the poverty level. The poverty in India has decreased compared to the past situation as per the 2011 economic statistics. Following the forecast, by 2020 it will be reduced and by 2050 poverty may be eradicated from India with negligible existence. It can be achieved when the Government of India takes the necessary steps and commits effectively for reducing the poverty. To do so, the Government of India should increase regular employment, raise funds for the small scale industries. Eradication of poverty from all sectors will definitely aid in the country's overall development". There is good improvement in using of technology from past 1990 to 2015 within all the agriculture, information technology, telecommunications, research labs, pharmaceutical industries, automotive industries. Smart systems and smart technologies brought more advance changes in economic development [2]. The economical interaction between nations has brought further growth in the international trading with additional investments and better infrastructure for the economic growth in various nations. Improved communication allows importing advanced techniques along with required equipment's for the better and rapid usage of available resources further helping in development of country's economy. India, as a country, is having immense potential to be among the top ranked in terms of maximizing investments, developing world class infrastructure and also in promoting other under developed nations to develop their economy." For assisting such under developed nations, the government of India has promoted the FDI (Foreign Direct Investment) for raising the economy and help in nation development. FDI investments have increased the total investments for the nation and it is leading towards more employment for the younger generation [35]. With this formulae India has step forward in reducing the poverty. International trading has become the major part of country's economy. All the nations are showing interest towards India and looking forward to increase their investments. The theory of international trade has been enriched by the study of strategic trade policy in the 80 s. Under the assumption of imperfect competition and scale economics Government can use export subsidies to lend support to its home firm for gaining market share in country, thus improving the globalization. There are many such implementations for the economic growth.

\section{Formulation of Economic Strategies}

Mainly all countries follow some standard trading activities, investments received in trading from all over the world by showing the country's resources, infrastructure, and manpower for the industries are useful. Introducing the benefits fetched from the investments for further growth will aid in economy in an exponential manner with time.. India is looking forward and encouraging more investments in all the aspects for the proper use of available resources [6].

Some of the trading companies have made huge investments in all the sectors like software industries, telecommunications, marketing, academic institutes, clothing, beverages, agriculture, electronic appliances, smart technologies, automotive sector, retails, food and beverages etc.

By implementation of all these aspects the country can gain employment for their young generation, and it will be reducing the level of poverty to some extent $[7,8]$. There are some methods for developing their industries economy:
1. Advertising
2. $\quad$ Marketing
3. Using of smart technologies
4. Developing new technologies
5. Paying employ strategies

\section{Advertisement}

When the organization, industry, company, needs development from the startup level it needs more advertisements regarding their products. Reaching people with the brands and products provide popularity as well as market share for newly launched startup organizations. Pushing the new products into the existing or new market requires well defined strategy for marketing. Advertisements can change the complete financial status of the company and the overall growth More market share automatically reflects in the organization's economic health. Indirectly this aids in overall economic growth.

*Corresponding author: Srihari T, Center for Biotechnology, Institute of Science and Technology, Jawaharlal Nehru Technological University, Hyderabad, India, E-mail: srihari.taneeru@rediffmail.com

Received May 18, 2015; Accepted May 23, 2015; Published May 30, 2015

Citation: Srihari T, Vinay CV (2015) Economic Growth: Measuring the Essential Elements. Bus Eco J 6: 156. doi:10.4172/2151-6219.1000156

Copyright: ( 2015 Srihari T, et al. This is an open-access article distributed under the terms of the Creative Commons Attribution License, which permits unrestricted use, distribution, and reproduction in any medium, provided the original author and source are credited. 
Designing and executing a successful advertisement requires constant effort and experimentation. It may include public figures such as film stars, sports personalities etc. and may use franchising models for better outcome Sports like soccer, cricket are much more popular for advertising the company products repeatedly. This results in growing the company standards with good economy.

Analysis says that in this competitive world without advertising, the company product may not survive or earn well in the market. Figure 1 shows the media of advertisement.

\section{Marketing}

For the good growth and development of the organization proper marketing is the only way to gain and reach the high level. Marketing itself remains the main criteria for the export and import of business. It develops the communication between groups, countries, organizations. It shows the huge results in the company's growth [9]. Marketing is mandatory for all the sectors like transportation, automotive sector, retail industries, telecommunications, pharma, research labs, hospitality, hotels, hubs and all the entertainment zones. Through this an organization gains more number of investments, stocks, increasing in share values, all these aspects may develop the company's economic growth. Figure 2 displays the marketing.

\section{Use of smart technologies}

The growth of the world depends on the usage of smart technologies and smart applications. Communications and interactions made much more advanced with these smart technologies. Smart technology

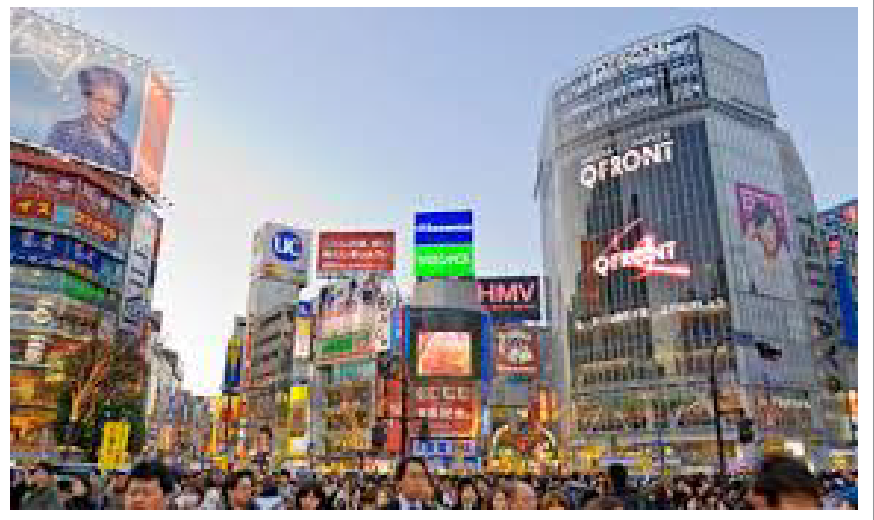

Figure 1: Media of advertisement.

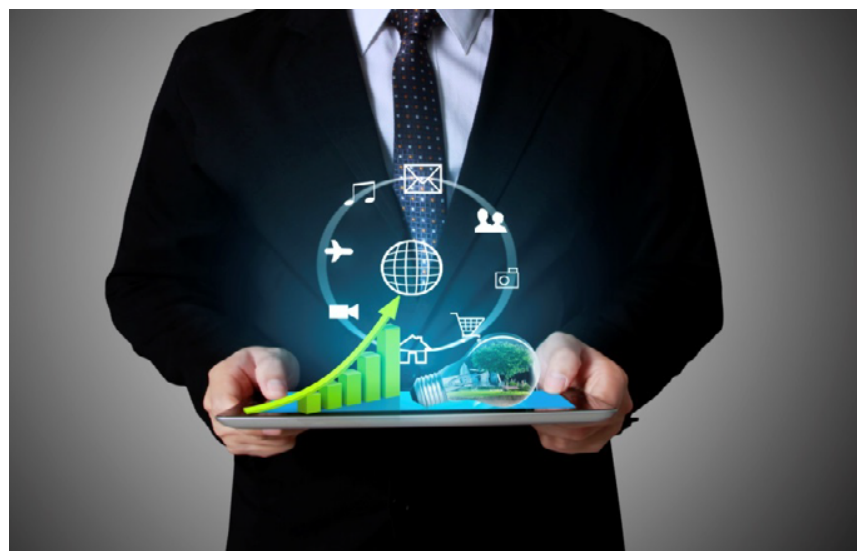

Figure 2: Global marketing



Figure 3: Use of smart technology

brought human closer and also allowed the usage of the resources and the necessary things in daily life. Some of the leading companies are showing huge dependence on the smart technologies. Compare to the past man has made many advances with smart techniques. Mainly laptops, I pads, mobiles made huge contribution to the world in all aspects, these activities lead to the company growth and economy of the country. Smart applications made the service providers closer to the public which in turn helped in regular activities, such as, paying bills, advance booking for travelling, entertainment, food and other online transactions. Now-a-days banks are also part of the smart technology which helped in making all transactions from respective banks in an easier way. Figure 3 shows the use of smart technology.

\section{Developing new technology}

For the growth in the competitive world any organization needs to develop new ideas with new techniques and more advance technology. All innovations and relevant discoveries should attract the common people with their easy and simple usage of techniques.

Comparing with the past ten years we are using the advanced technology in all aspects, such as, telephone to cellular phone(mobile phone),electronic appliances with digitalized version, automotive sector has developed technology for extra milage, digital meters, GIS technology etc. Growth in agriculture with using more advanced techniques like introducing new paddy cutter machines, usage of better pesticides, fertilizers etc. Health care sector too showed marvelous advancement through applying latest technologies in diagnosis and other issues.

Research labs made more efforts with funds in discovering new technologies which were useful for the mankind in a better way. Information Technology has made contribution in building up the new technology. With the help of new technology, the Government became much friendly with the entire sector and contributing in gaining the economy growth. There is an increase in the employment with new technology.

\section{Maintaining strategies}

When the country is developing in all the aspects it is made of contribution from all the individuals specially workers, employees, youth, students every individual. The government is responsible for taking part within all the individuals so the unity makes growth in all the aspects [10]. Like way the organization should follow the roles and 


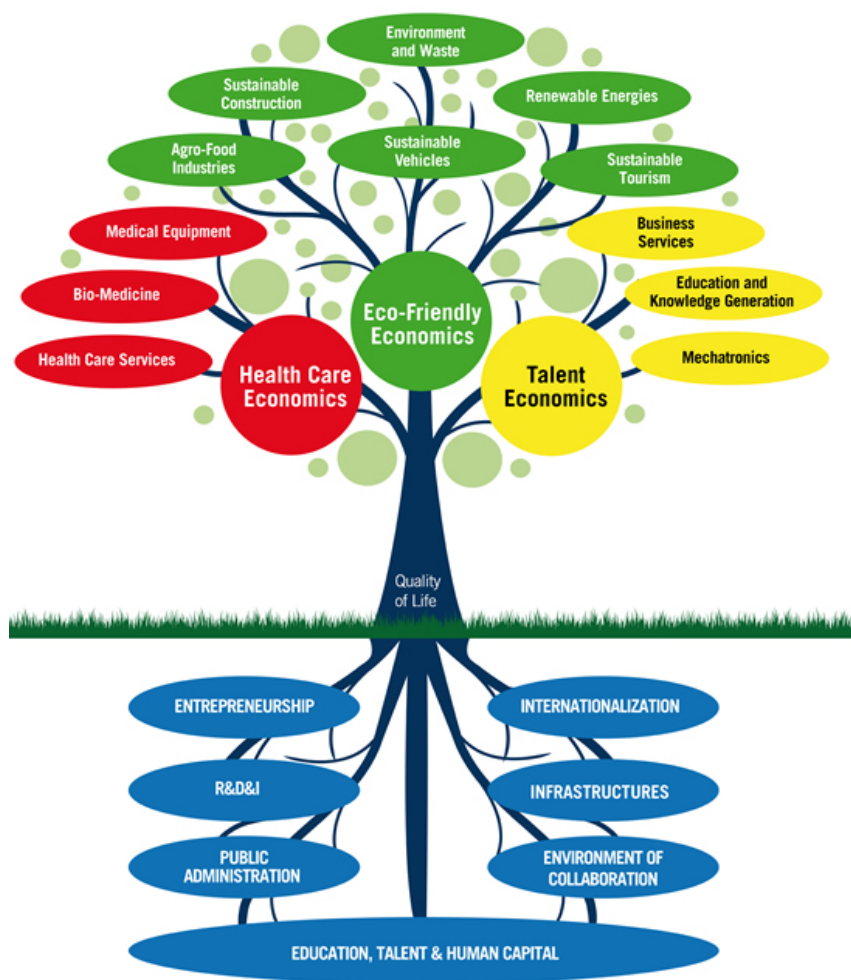

Figure 4: Displays the strategies for economic growth.

responsibilities in building up the administration, paying the employees for their hard work. It will lead to growth of the organization much faster in all the aspects of economy. Figure 4 displays the Strategies for economic growth.

\section{Conclusion}

Economics remains the spine of a nation and determines the future and fate of the country. Proper planning for future, identifying potential economic growth factors and nourishing them should be adopted as a standard policy for any country. Third world countries have been a sufferer in terms of economics for a long time. Very slow improvement and large social and economic burdens are not allowing changing the situation. But in this darkness countries like China, India or in general BRIC (Brazil, Russia, India and China) kind of organization and association have shown promises. Cooperation and planning may aid a lot and alter the situation in coming future. The altering economic condition of the Indian peninsular is an indication of such change. As the present financial reports shows, India is coming up as an emerging economic power. Attaining a powerful economic position and maintaining the constant growth for a nation is challenging and dynamic. Application of technologies, implementation of effective policies and proper analysis and forecasting of the global economic conditions will definitely help us to sustain a respectful economic growth and build a better economy.

\section{References}

1. Richard J Cebula (2014) A Recipe for Promoting Economic Growth and Higher Living Standards in the 21st Century. Journal of Global Economics.

2. Rok Spruk (2013) Economic Growth and Income Convergence in Transition: Evidence from Central Europe Journal of Global Economics.

3. Economic Growth (2015) Investopedia

4. Akamatsu K (1962) A historical pattern of economic growth in developing countries 1: 13-25.

5. Arpita M, Patel N (2005) FDI in retail sector, India

6. Singh PN, Huang SC (2010) Some Socio-Cultural and Psychological Determinants of Advertising in India: A Comparative Study 57: 113-121.

7. Raymond H, Andrew TN, Chip EM (2005) Examining the influence of articles involving marketing history, thought, and theory: A Journal of Marketing citation analysis 1950s-1990s. Marketing Theory 5: 323-336.

8. Rustam Lalkaka (2010) Technology business incubators to help build an innovation-based economy. Journal of Change Management 3: 167-176.

9. Kumar NA, Joseph J (2014) A Study on Consumer Behavior towards Fmcg Products among the Rural- Suburban Hhs of Ernakulam. Journal of Global Economics.

10. Dani Rodrik (2005) Growth Strategies. In: Philippe Aghion (ed.) Handbook of Economic Growth 1: 967-1014. 